\title{
Durabilidade de concretos produzidos com agregado graúdo proveniente de resíduo de cerâmica vermelha
}

\section{Durability of concrete produced with coarse aggregate from red ceramic waste}

Luciano Passos ${ }^{1}$, Armando Lopes Moreno Junior ${ }^{2}$, Carlos Eduardo Marmorato Gomes ${ }^{3}$

\footnotetext{
${ }^{1}$ Universidade Estadual de Campinas - UNICAMP, Faculdade de Engenharia Civil, Arquitetura e Urbanismo, Departamento de Estruturas, Campinas, São Paulo, Brasil. e-mail: lupa1602@unicamp.br

${ }^{2}$ Universidade Estadual de Campinas - UNICAMP, Faculdade de Engenharia Civil, Arquitetura e Urbanismo, Departamento de Estruturas, Campinas, São Paulo, Brasil. e-mail: armoreno@unicamp.br

${ }^{3}$ Universidade Estadual de Campinas - UNICAMP, Faculdade de Engenharia Civil, Arquitetura e Urbanismo, Departamento de Construção Civil, Campinas, São Paulo, Brasil. e-mail: cemgomes@unicamp.br
}

\section{RESUMO}

O emprego de resíduo cerâmico na produção do concreto pode ser considerado uma ação viável em prol da sustentabilidade na indústria da construção civil. No entanto, faz-se necessário, o estudo das propriedades físicas e mecânicas do concreto produzido com este resíduo, garantindo segurança e necessária vida útil das edificações. Neste sentido, este trabalho avalia a durabilidade dos concretos produzidos com agregados provenientes de resíduos de cerâmica vermelha visando seu emprego na produção de elementos estruturais em concreto armado. Para tanto, foram produzidos traços com substituição do agregado graúdo natural pelo resíduo de cerâmica vermelha nos teores de 40 e 100\% de substituição, em volume. Foram realizadas análises de carbonatação, absorção por permeabilidade capilar, permeabilidade ao ar e penetração por cloretos para verificação da durabilidade, bem como a verificação de suas propriedades mecânicas, em especial, resistência à compressão axial. Os resultados demonstraram menor permeabilidade para os concretos produzidos com resíduo cerâmico e, consequentemente, menor ataque por cloretos e carbonatação para misturas com até $40 \%$ de resíduo cerâmico, o que sugere, consequentemente, que elementos estruturais executados com estas misturas alternativas estariam menos propensos à corrosão das armaduras. A análise por microscopia eletrônica por varredura evidenciou uma redução no diâmetro dos poros capilares, resultado da melhor hidratação da fase cimentícia por meio do fenômeno conhecido por cura interna, proporcionado pelo emprego do agregado cerâmico reduzindo, também, a espessura da zona de transição interfacial entre o agregado e a matriz cimentícia.

Palavras chaves: resíduo de cerâmica vermelha, concreto, durabilidade, resistência mecânica.

\section{ABSTRACT}

The use of ceramic waste in concrete can be evaluated as a viable action in favor of sustainability in the construction industry. However, it is necessary, the study of the physical and mechanical properties of the concrete made with residue, guaranteeing the safety and the recovery of the useful life of the buildings. In this sense, this work evaluated the production of concrete materials with aggregates derived from concrete residues in the armed plane. In order to achieve this, a gradual change of the natural high yield was introduced by the red ceramic process at 40 and $100 \%$ substitution by volume. Carbonation, absorption by capillary permeation, air permeability and penetration of chlorides were obtained for the verification of durability, as well as a record of their mechanical properties, especially axial compression strength. The results showed lower permeability for the concretes with the ceramic and, consequently, lower chloride attack and carbonation for mixtures with up to $40 \%$ ceramic waste, which suggests, therefore, that the elements executed with these alternative blends are less prone to corrosion of the reinforcements. The analysis by scanning electron microscopy evidenced a reduction in the diameter of the capillary pores, as a result of the better hydration of the cement phase through the phenomenon known as internal cure, provided by the use of the ceramic aggregate, also reducing the thickness of the interfacial transition zone between the aggregate and the cement matrix. 
Keywords: red ceramic waste, concrete, durability, mechanical resistance.

\section{INTRODUÇÃO}

A crescente expansão imobiliária implica na geração de grande quantidade de resíduos, que são descartados muitas vezes em locais inapropriados, comprometendo áreas de preservação ambiental e de mananciais. Vale observar que grande parte destes resíduos podem ser reaproveitados. Segundo Campos e Paulon [1], a indústria cerâmica que engloba desde o tijolo cerâmico, passando pelos revestimentos e louças sanitárias, e atinge os isoladores elétricos de porcelana, possui um elevado índice de descarte de material durante o processo de fabricação, transporte e eventual substituição. É premente, neste caso, o estudo de formas de reuso deste material, sendo uma delas o emprego deste resíduo cerâmico como agregado graúdo na produção de concretos para fins estruturais. Neste caso, os elementos estruturais devem atender parâmetros necessários de projeto que visam, sobretudo, a segurança e a durabilidade das edificações.

Segundo Medeiros et al [2], a durabilidade é o resultado da interação entre a estrutura de concreto, o ambiente e as condições de uso, de operação e de manutenção. Portanto, não é uma propriedade inerente ou intrínseca à estrutura, à armadura ou ao concreto. Uma mesma estrutura pode ter diferentes comportamentos, ou seja, diferentes respostas de durabilidade no tempo, conforme seus componentes e forma de utilizá-la.

Para a ABNT NBR 6118 [3], durabilidade "consiste na capacidade da estrutura resistir às influências ambientais previstas e definidas em conjunto pelo autor do projeto estrutural e o contratante, no início dos trabalhos de elaboração do projeto".

Os métodos de avaliações de durabilidade podem ser diretos ou indiretos. Os métodos indiretos que avaliam a durabilidade em laboratório são os ensaios de carbonatação, que tem por objetivo verificar a suscetibilidade do concreto frente ao $\mathrm{CO}_{2}$ uma vez que a consequente redução do $\mathrm{pH}$ da matriz pode proporcionar uma despassivação e corrosão da armadura. Também, o ensaio de absorção por capilaridade, que tem por objetivo verificar a porosidade da camada de cobrimento dos concretos frente ao ataque por meio de águas ácidas, sulfatadas e outros agentes que possam atacar a armadura por meio dos poros capilares e, ainda, as análises de penetração de íons cloreto e o de permeabilidade ao ar.

A durabilidade dos concretos produzidos com agregados reciclados, no geral, segundo a literatura, pode ser influenciada pela porosidade e absorção de água destes materiais.

Segundo Raisdorfer [4], a determinação da absorção por capilaridade pode ser um bom indicativo das condições da porosidade da superfície do concreto, sendo assim, essa porosidade o caminho preferencial de gases e líquidos. Quanto menor for o diâmetro do capilar, maior será a ascensão do líquido no seu interior. Por outro lado, quanto maior for o diâmetro do capilar, maior será a quantidade total de água absorvida.

Enfim, todos estes métodos indiretos avaliam a permeabilidade do concreto e a facilidade de que substâncias agressivas possam penetrar em seus poros.

No caso da durabilidade dos concretos com agregados reciclados, poucos são os estudos observados na literatura que abordam a avaliação destes parâmetros para concretos produzidos com agregados graúdos provenientes de resíduos da indústria cerâmica.

Leite [5] demonstrou a possibilidade de haver reação pozolânica entre um agregado cerâmico e a matriz cimentícia. Neste estudo, foi verificado que, ao contrário do concreto convencional, a zona de transição entre matriz e agregado cerâmico não pode ser identificada. Constatou-se, também, a ocorrência de produtos de hidratação na superfície porosa e rugosa do agregado cerâmico devido à absorção da pasta de cimento, o que contribui para aderência e a densificação entre o agregado e a pasta. A reação pozolânica também foi observada por Vieira et al [6], que fizeram estudos com substituição de agregado graúdo por agregado reciclado proveniente de tijolos cerâmicos, sendo demonstrado que aumentando-se o teor de agregado reciclado a absorção por capilaridade diminui em virtude da ação pozolânica destes resíduos.

Levy [7] apresentou resultados de ensaios relativos à durabilidade de concretos produzidos com resíduos de concreto e de alvenaria de blocos cerâmicos, concluindo que a adição de agregados miúdos de alvenaria ao concreto pode reduzir a carbonatação. A substituição de $50 \%$ de areia natural por areia de alvenaria provocou uma redução na profundidade de carbonatação em torno de 33\%. Este estudo diverge do apresentado por Silva et al [8] que, ao avaliarem o comportamento de concretos feitos com agregados reciclados de construção e demolição frente a carbonatação, demonstraram que quanto maior o teor de substituição, maior é a profundidade de carbonatação. Neste estudo, verificou-se, também, um aumento progressivo na profundidade de carbonatação e de penetração de íons cloretos para maiores teores de agregados reciclados, sendo justificado pela maior relação água/cimento adotada.

Ainda em relação à velocidadde de carbonatação, Kulakowski apud Reis [9], aponta que para relações 
água/cimento compreendidas entre 0,45 e 0,5 o comportamento do concreto face à carbonatação é bastante crítico.

A durabilidade de concreto e resíduos cerâmicos também foi estudada por Senthamarai et al [10]. Neste estudo, foram empregadas cerâmicas provenientes de isoladores elétricos na forma de agregado graúdo, para verificação da permeabilidade por absoção capilar, volume de vazios, sorção e difusão de cloretos em concretos produzidos com diferentes relações água-cimento, não sendo observadas alterações significativas nos compósitos alternativos quando comparados aos de referência.

Nos estudos de Lotfi et al [11], a durabilidade de concretos com agregados reciclados foi estudada por meio da substituição de agregado graúdos nos teores de 20, 50 e $100 \%$, sendo então realizados ensaios de carbonatação e permeabilidade ao ar. Ficou evidenciado que, substituindo mais de $50 \%$ do agregado graúdo natural pelo reciclado, o concreto não seria recomendado para aplicações sujeitas a elevados níveis de agressividade ambiental.

Corominas et al [12] analisaram o efeito de vários tipos de agregados reciclados adotando blendas compostas por $22,2 \%$ de concreto, $9,8 \%$ de resíduos de construção em geral e $67,3 \%$ de resíduos de cerâmica. Para verificação da durabilidade os ensaios adotados neste estudo foram ataque por cloretos conforme (ASTM C1202): Standard Test Method for Electrical Indication of Concrete's Ability to Resist Chloride Ion Penetration [13] e, absorção por permeabilidade capilar segundo o método preconizado por (SIA 162/1): Swiss Standard - Succión Capilar [14]. Ao final os autores concluiram que substituições de até 50\% de agregado graúdo pelo reciclado não prejudicou a durabilidade. Observam, no entanto, que os concretos contendo cerâmica como agregado miúdo, com teores de até 30\%, alcançaram maior resistência à compressão, maior resistência à penetração de íons cloreto e melhores resultados nas propriedades de durabilidade em idades mais avançadas.

Como observado, a utilização dos resíduos provenientes de cerâmica vermelha na produção de concretos para fins estruturais, pode contribuir para mitigar os impactos ambientais e aumentar o nível de ações sustentáveis aplicadas na construção civil, em especial, devido à possibilidade de escassez de agregados naturais em grandes centros. Contrapondo, observa-se regiões que se caracterizam como grandes produtoras de resíduos de contrução e demolicação (RDC) com descarte desgovernado em aterros comprometendo, assim, a qualidade de vida.

Neste contexto, como contribuição ao meio técnico/científico, nesta pesquisa buscou-se avaliar a durabilidade de concretos produzidos com agregados provenientes de resíduos de cerâmica vermelha, com vistas à possibilidade de seu emprego na produção de elementos estruturais em concreto armado para obras de pequeno porte, aquelas onde a resistência a compressão do concreto requerida esteja ao redor de $20 \mathrm{MPa}$.

\section{MATERIAIS E METODOLOGIA}

\subsection{Materiais}

Neste estudo foram adotados três traços de concreto. Para cada traço foram moldados 96 corpos de prova cilíndricos de $100 \mathrm{~mm}$ de diâmetro e $200 \mathrm{~mm}$ de altura, sendo que destes, 18 amostras foram para ensaios de carbonatação, 36 para ensaios de absorção por permeabilidade capilar, 18 para ensaios de permeabilidade ao ar, 12 para ensaios de penetração de cloretos e, 12 para ensaios de resistência à compressão, modulo de deformação e tração por compressão diametral. A Tabela 1 apresenta os traços adotados. Foi fixada a relação água/cimento em 0,49 , e o consumo de cimento de $372 \mathrm{~kg} / \mathrm{m}^{3}$, prevendo resistência à compressão mínima de $20 \mathrm{MPa}$. 
Tabela 1: Misturas de concreto para ensaios finais.

\begin{tabular}{c|c|c|c|c|c|c}
\hline TRAÇO & $\begin{array}{c}\text { CIMENTO } \\
\text { CPII-E 32 } \\
(\mathbf{k g})\end{array}$ & $\begin{array}{c}\text { AGREGADO } \\
\text { MIÚDO NA- } \\
\text { TURAL } \\
\mathbf{( k g )}\end{array}$ & $\begin{array}{c}\text { AGREGADO } \\
\text { GRAÚDO NA- } \\
\text { TURAL } \\
\mathbf{( k g )}\end{array}$ & $\begin{array}{c}\text { AGREGADO } \\
\text { GRAÚDO } \\
\text { CERÂMICO } \\
\mathbf{( k g )}\end{array}$ & $\mathbf{a / c}$ & $\begin{array}{c}\text { Abatimento } \\
(\mathbf{m m})\end{array}$ \\
\hline $\mathbf{R E F}$ & 1 & 2 & 3 & 0 & 0,49 & 50 \\
\hline $\mathbf{S 4 0}$ & 1 & 2 & 1,8 & 0,67 & 0,49 & 50 \\
\hline $\mathbf{S 1 0 0}$ & 1 & 2 & 0 & 1,62 & 0,49 & 50 \\
\hline
\end{tabular}

As características dos agregados empregados são apresentadas na-Tabela 2.

Tabela 2: Propriedades dos materiais empregados.

\begin{tabular}{c|c|c|c|c}
\hline Propriedade & Método & $\begin{array}{c}\text { Agregado de resíduo } \\
\text { cerâmico }\end{array}$ & $\begin{array}{c}\text { Agregado graúdo } \\
\text { convencional }\end{array}$ & $\begin{array}{c}\text { Agregado miúdo } \\
\text { (areia) }\end{array}$ \\
\hline $\begin{array}{c}\text { Massa Específica } \\
\left.\text { Seca (g/cm }{ }^{3}\right)\end{array}$ & $\begin{array}{c}\text { NBR NM } \\
53[15], 52[16]\end{array}$ & 1,77 & 2,89 & 2,63 \\
\hline D.M.C (mm) & NBR NM 248[17] & 19 & 19 & 4,8 \\
\hline M.F.(mm) & NBR NM 248[17] & 6,41 & 1,69 & 1,47 \\
\hline $\begin{array}{c}\text { Massa Unitária } \\
\left(\mathrm{g} / \mathrm{cm}^{3}\right)\end{array}$ & NBR NM 45[18] & 0,95 & 0 & 0 \\
\hline $\begin{array}{c}\text { Torrões de Argila e } \\
\text { Materiais Friá- } \\
\text { veis(\%) }\end{array}$ & NBR 7218[19] & 0 & 0.69 & 2,37 \\
\hline $\begin{array}{c}\text { Teor de Material } \\
\text { Passante na Peneira } \\
75 \mu m(\%)\end{array}$ & NBR NM 46[20] & - & 1,2 & 0,15 \\
\hline $\begin{array}{c}\text { Absorção de Âgua } \\
(\%)\end{array}$ & $\begin{array}{c}\text { NBR NM 53[15] } \\
\text { /NM30[21] }\end{array}$ & 19 & & \\
\hline
\end{tabular}

A Figura 1 ilustra a análise granulométrica dos agregados graúdos e, na Figura 2, pode ser observada a morfologia do agregado reciclado, predominantemente angular e alongada. A dimensão característica do agregado graúdo convencional se apresentou entre os diâmetros de $9,5 \mathrm{~mm}$ a $25 \mathrm{~mm}$ e, sua dimensão máxima característica, bem como, o módulo de finura foi apresentada na Tabela 2. O agregado graúdo reciclado foi obtido do material resultante da trituração de resíduos de fábricas de produção de telhas e blocos cerâmicos da região de Campinas-SP.

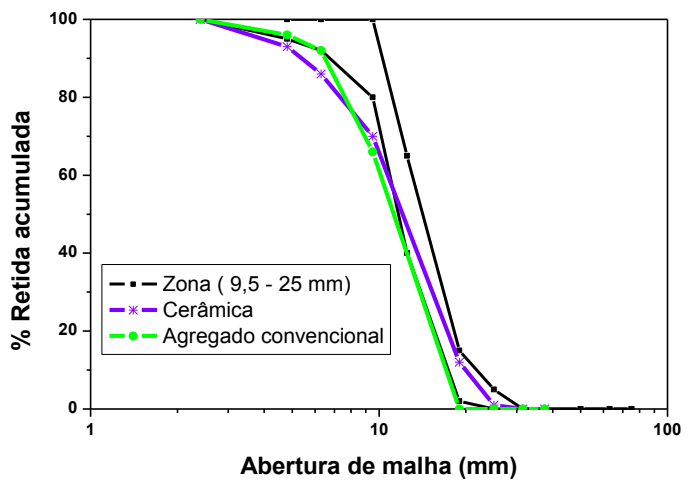

Figura 1: Curvas granulométricas dos agregados graúdos. 


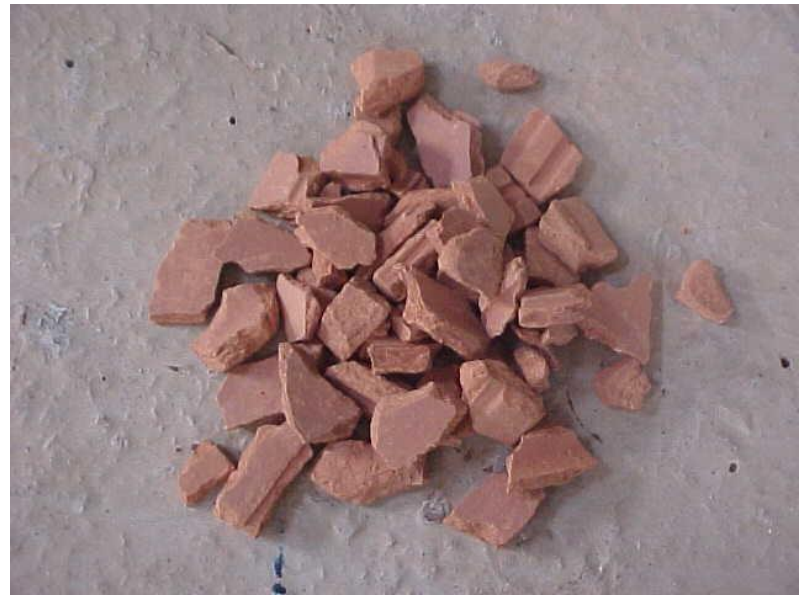

Figura 2: Amostra do agregado graúdo proveniente de resíduo cerâmico.

Considerando a elevada absorção de água promovida pelo resíduo cerâmico, procedeu-se prévia umidificação destes agregados com $80 \%$ da água de absorção, procedimento similar ao executado por Correia et al [22] e indicado pela NBR 15116 [23]. Após a moldagem, os corpos de prova foram colocados em tanques com água até o dia previsto para o ensaio.

\subsection{Ensaios de carbonatação}

Para medir a profundidade de carbonatação, foi realizado processo acelerado, baseado nos procedimentos propostos pela RILEM (TC 116-PCD de 1999 e CPC-18 de 1988) [24].

Os ensaios foram feitos em uma câmara de carbonatação acelerada adaptada, conforme Figura 3.

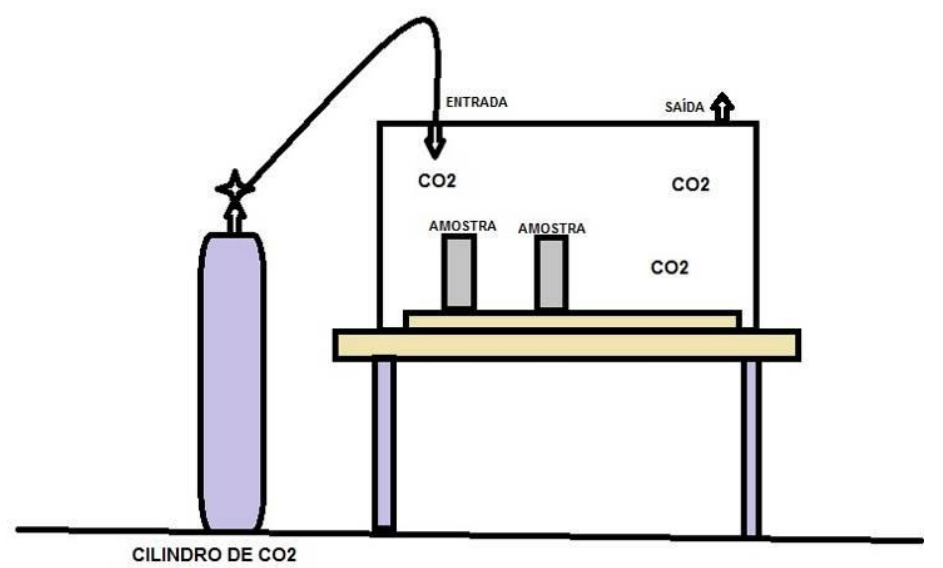

Figura 3: Esquema da câmara para carbonatação acelerada.

Para as análises de carbonatação foram usados corpos de prova cilíndricos com $100 \mathrm{~mm}$ de diâmetro por $200 \mathrm{~mm}$ de altura. Após 28 dias de cura, as amostras foram colocadas na câmara de carbonatação acelerada. Os ensaios foram feitos após 28, 90 e 180 dias de ataque por dióxido de carbono $\left(\mathrm{CO}_{2}\right)$.

Para cada data prevista de ensaio as amostras foram retiradas da câmara de carbonatação e submetidas à compressão diametral. Após, foi aspergida uma solução de $1 \%$ de fenolftaleína em $70 \%$ de álcool etílico e $29 \%$ de água destilada.

O ensaio é colorimétrico, ou seja, a região que ficar avermelhada não foi carbonatada. Para medição foi utilizado uma escala em milímetros como indicado na Figura 4 sendo utilizados dois corpos de prova para cada idade de ensaio. 


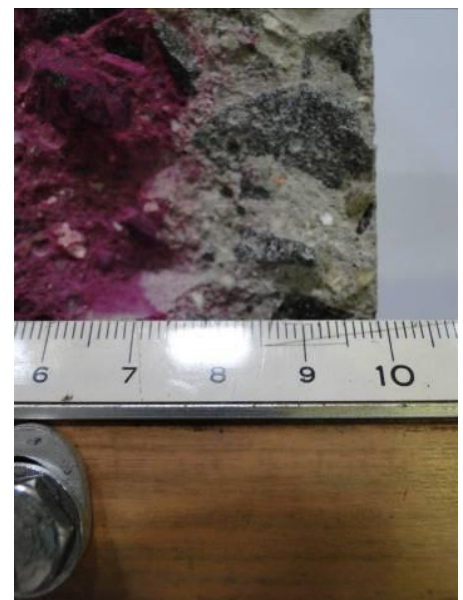

Figura 4: Medição da profundidade de carbonatação.

\subsection{Absorção por permeabilidade capilar}

Para cada traço foi realizado ensaio de absorção por permeabilidade capilar em 4 corpos de prova de $100 \mathrm{~mm}$ de diâmetro e $200 \mathrm{~mm}$ de altura, nas idades de 63, 95 e 180 dias, segundo NBR 9779 [25], conforme Figura 5 .

Neste ensaio a absorção de água foi medida segundo pesagens dos corpos de prova aos 5, 10, 15 e 30 minutos e, 1, 2, 4, 6 e 24 horas de ensaio. Ao final os corpos de provas foram ensaiados à compressão diametral para medição da altura de penetração da água, em milímetros.

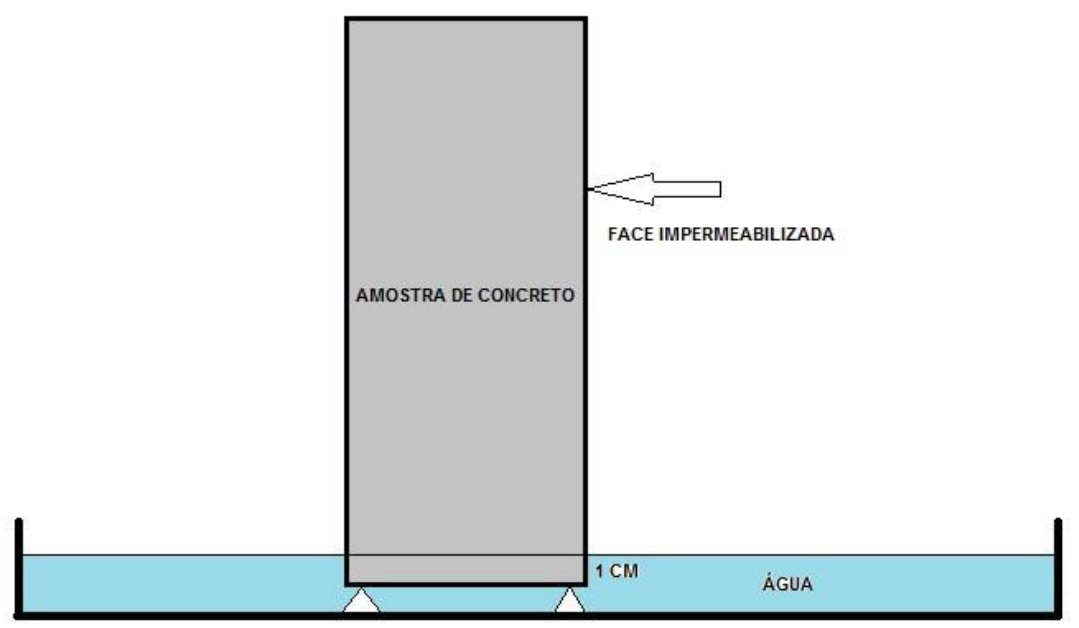

Figura 5: Esquema de ensaio de absorção por permeabilidade capilar. 


\subsection{Permeabilidade ao ar}

Os ensaios de permeabilidade ao ar foram realizados segundo a metodologia proposta por Thenoz [26] e adaptada por Pereira [27]. Para a realização dos ensaios de permeabilidade ao ar do concreto, foram cortadas amostras (100 mm x $50 \mathrm{~mm}$ ) do centro dos corpos-de-prova cilíndricos (100 mm x $200 \mathrm{~mm})$. Antes da realização dos ensaios de permeabilidade ao ar do concreto, as amostras permaneceram 24 horas em estufa à temperatura de $50^{\circ} \mathrm{C}$, após esta etapa elas foram impermeabilizada nas laterais e posicionadas no aparelho ( Figura 6), devidamente vedada para que o ar passe pelo concreto.

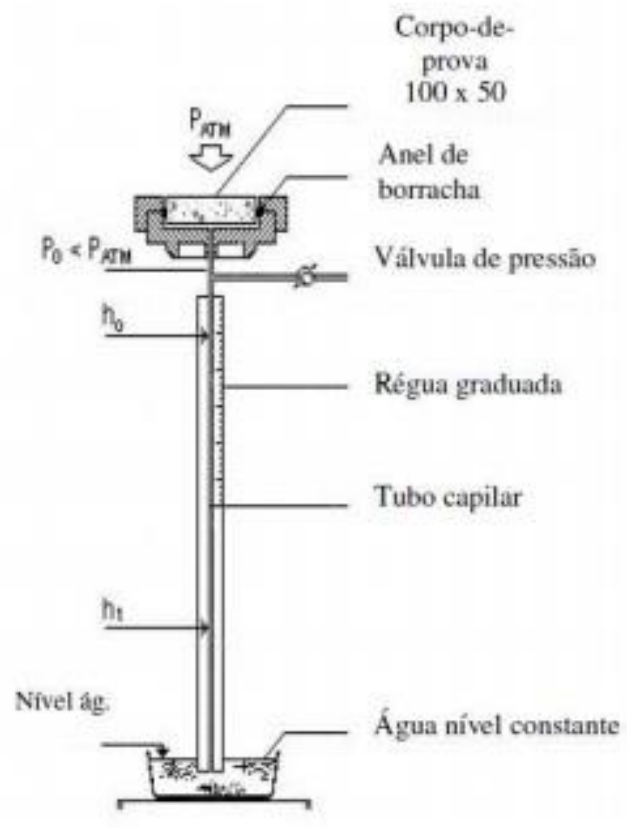

Figura 6: Esquema de ensaio de absorção por permeabilidade ao ar. Fonte: Adaptado de Pereira [27].

\subsection{Determinação da frente de penetração de cloretos}

O objetivo deste ensaio foi verificar a profundidade de penetração dos íons cloreto no concreto após ciclos de imersão e secagem em solução padrão com concentração de $3,5 \%$ de cloreto de sódio $(\mathrm{NaCl})$. Este método consiste na aspersão de nitrato de prata $\left(\mathrm{AgNO}_{3}\right)$ conforme procedimento UNI 7928 Determination of chloride lon penetration da Unificaciones Del) [28]. Após 95 dias de cura os corpos de prova foram submetidos a 8 ciclos (Figura 7), após esta etapa, as amostras cilíndricas de diâmetro de $100 \mathrm{~mm}$ e altura de $200 \mathrm{~mm}$ foram rompidas à tração por compressão diametral e, após, realizada uma aspersão de uma solução de nitrato de prata com concentração de 0,1 molar (M) na superfície exposta. Em seguida os corpos de prova foram levados a um ambiente iluminado para reação da solução com os íons cloretos sendo as leituras realizadas após 10 minutos. 


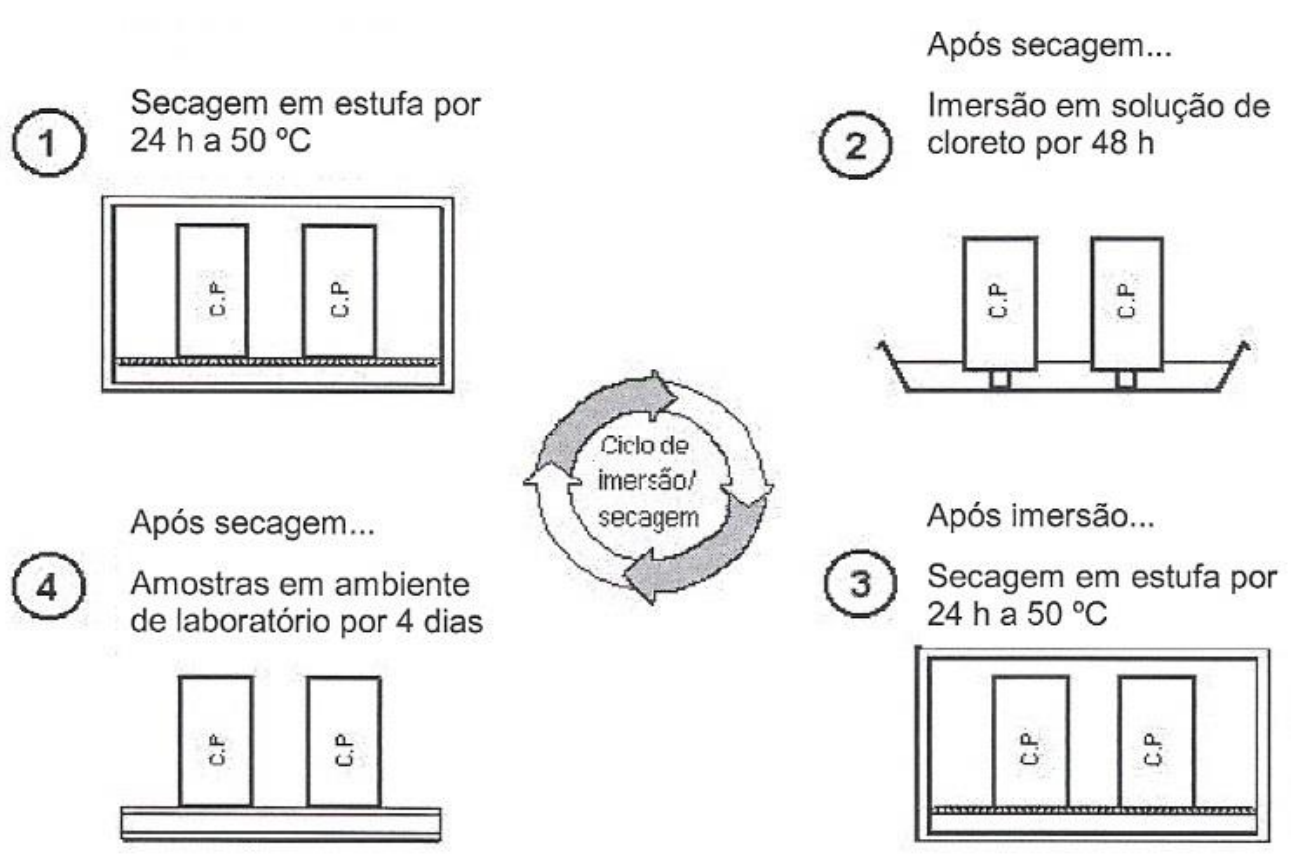

Figura 7: Esquema para ensaio de penetração de cloretos. Fonte: Adaptado de Ferreira Jr [29].

\section{RESULTADOS E DISCUSSÕES}

Na Tabela 3 são apresentadas as propriedades mecânicas dos concretos analisados, sendo identificado por: $\mathbf{f}_{\mathbf{c} 7}$, a resistência à compressão do concreto aos sete dias de idade; $\mathbf{f}_{\mathbf{c 2 8}}$, a resistência à compressão aos vinte e oito dias de idade; $\mathbf{f}_{\mathbf{t 7}}$, a resistência à tração por compressão diametral aos sete dias de idade; $\mathbf{f}_{\mathbf{t 2 8}}$, a resistência à tração por compressão diametral aos vinte e oito dias de idade e; $\mathbf{E}_{\mathbf{c} 7} \mathbf{e} \mathbf{E}_{\mathbf{c 2 8}}$, o módulo de deformação dos concretos aos sete dias de idade e vinte e oito dias, respectivamente

Tabela 3: Propriedades mecânicas dos concretos analisados.

\begin{tabular}{r|c|c|c|c|c|c}
\hline CONCRETO & $\begin{array}{c}\mathbf{f}_{\mathrm{c7}} \\
(\mathbf{M P a})\end{array}$ & $\begin{array}{c}\mathbf{f}_{\mathrm{t} 7} \\
(\mathbf{M P a})\end{array}$ & $\begin{array}{c}\mathbf{E}_{\mathrm{c7}} \\
(\mathbf{G P a})\end{array}$ & $\begin{array}{c}\mathbf{f}_{\mathbf{c 2 8}} \\
(\mathbf{M P a})\end{array}$ & $\begin{array}{c}\mathbf{f}_{\mathbf{t} 28} \\
(\mathbf{M P a})\end{array}$ & $\begin{array}{c}\mathbf{E}_{\mathrm{c28}} \\
(\mathbf{G P a})\end{array}$ \\
\hline $\mathbf{R E F}$ & 24,26 & - & 20,00 & 30,00 & 3,34 & 22,10 \\
\hline $\mathbf{S 4 0}$ & 20,38 & 2,21 & 18,05 & 26,22 & 2,63 & 17,45 \\
\hline $\mathbf{S 1 0 0}$ & 16,43 & 2,15 & 8,0 & 19,04 & 2,23 & 11,30 \\
\hline
\end{tabular}

\subsection{Carbonatação do concreto}

Conforme Figura 8, pode-se observar que todos os concretos apresentaram profundidade de carbonatação excessiva, em conformidade a Kulakowski apud Reis [9], que afirma que relações água/cimento entre 0,45 e 0,5, o comportamento do concreto frente à carbonatação é bastante crítico e, uma vez que, optou-se em trabalhar com concretos com baixo consumo de cimento e relação água/cimento relativamente alta, o que implica no aumento da porosidade dos concretos analisados. Entretanto, pode se verificar que os concretos com agregado graúdo com emprego de resíduo cerâmico apresentaram profundidade de carbonatação menores comparados ao concreto de referência (REF). 


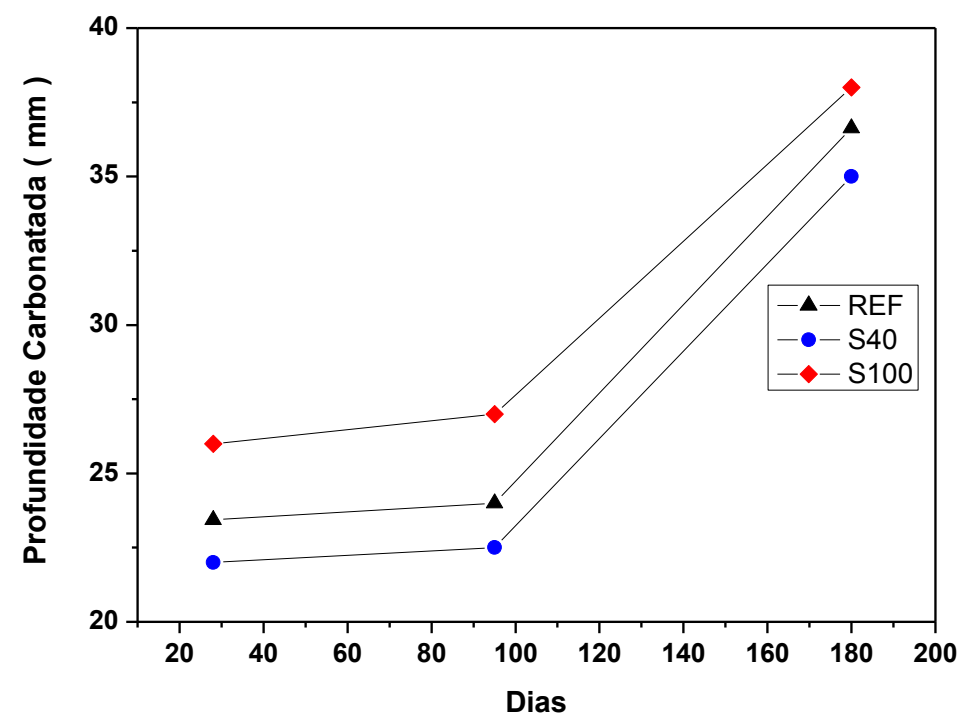

Figura 8: Profundidade de carbonatação nos concretos.

A diminuição da profundidade de carbonatação nos concretos alternativos (Figura 8) pode estar associada à menor porosidade da matriz cimentícia, uma vez que a absorção de água do resíduo cerâmico influencia diretamente na relação água/cimento e, também, pode possibilitar sua hidratação ao longo do tempo, entendida, assim, como uma cura interna. Ambos os fenômenos, colaboram para maior compacidade da matriz cimentícia e, consequente, diminuição da carbonatação, como também foi observado por Leite [5] que demonstrou a possibilidade de haver reação pozolânica entre um agregado cerâmico e a matriz cimentícia. Dessa forma, torna-se claro que tanto a absorção dos agregados cerâmicos e quanto à cura interna são aspectos que devem ser considerados no controle tecnológicos dos concretos alternativos.

\subsection{Absorção por permeabilidade capilar}

Os ensaios de absorção por permeabilidade capilar foram realizados e os resultados médios para 63,95 e 180 dias de idade são apresentados na Tabela 4.

Tabela 4: Absorção por permeabilidade capilar.

\begin{tabular}{c|c|c|c}
\hline \multirow{2}{*}{ Misturas } & $\mathbf{6 3}$ dias & $\mathbf{9 5}$ dias & $\mathbf{1 8 0 ~ d i a s}$ \\
\cline { 2 - 4 } & $\begin{array}{c}\text { Média/desvio } \mathbf{p a -} \\
\text { drão(g/cm }\end{array}$ & $\mathbf{( g / \mathbf { c m } ^ { 2 } )}$ & $\mathbf{( g / \mathbf { c m } ^ { 2 } )}$ \\
\hline REF & $1,04 / 0,07$ & $0,77 / 0,11$ & $0,64 / 0,06$ \\
\hline S40 & $0,65 / 0,10$ & $0,78 / 0,10$ & $0,77 / 0,02$ \\
\hline S100 & $0,40 / 0,13$ & $0,53 / 0,04$ & $0,84 / 0,16$ \\
\hline
\end{tabular}

Conforme apresentado na Tabela 4 , no concreto de referência observou-se uma redução da absorção capilar nas idades de 95 e 180 dias. Isto se deve à diminuição na porosidade da matriz ao logo do tempo, oriunda da hidratação contínua do cimento Portland com consequente diminuição dos poros capilares .

A diminuiição da absorção, no entanto, não foi verificada para os concretos com adição de $40 \%$ de agregado cerâmico. Para esta composição, foi verificada uma tendência de absorção maior para as idades mais avançadas, corroborando com a teoria de Raisdorfer [4], ou seja, é possível a ocorrência de diâmetros capilares menores compostos por produtos da hidratação do cimento, que tendem a ter maior poder de sucção. O mesmo foi observado por Corominas et al [12], quando empregou a substituição de até 50\% do agregado graúdo.

Para os concretos com emprego de $100 \%$ de agregado graúdo cerâmico (S100), pode-se observar um 
aumento significativo da sucção nas idades mais avançadas de 63 a 180 dias.

\subsection{Permeabilidade do concreto ao ar}

Na Figura 9 são apresentados os resultados obtidos no permeâmetro e os respectivos tempos para passagem do fluxo de ar.

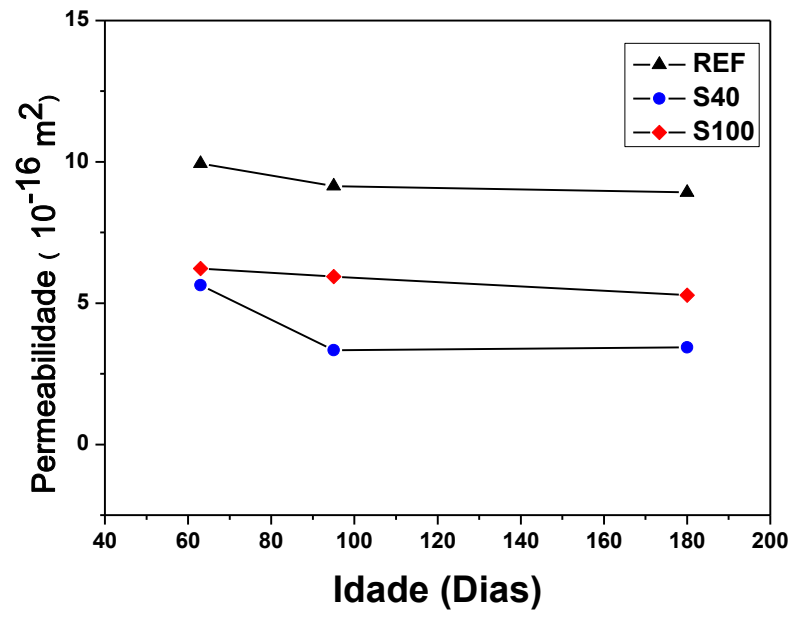

Figura 9: Permeabilidade ao ar nos concretos.

Em conformidade com os resultados anteriores, pode-se observar, também, que os concretos com substituição de agregado graúdo natural pelo reciclado de cerâmica vermelha foram os que apresentaram melhor desempenho, ou seja, menor permeabilidade (Figura 10).

Para idades mais avançadas, também foi verificada a diminuição do coeficiente de permeabilidade dos concretos analisados, corroborando o fechamento dos poros capilares conforme evolução da hidratação da matriz cimentícia.

\subsection{Penetração de cloretos}

Conforme apresentado na Figura 10, a profundidade de penetração de íons cloretos foi menor conforme aumento do teor de substituição do agregado natural pelo reciclado de resíduo de cerâmica vermelha. Estes resultados estão em consonância com o observado por Corominas et al [12].

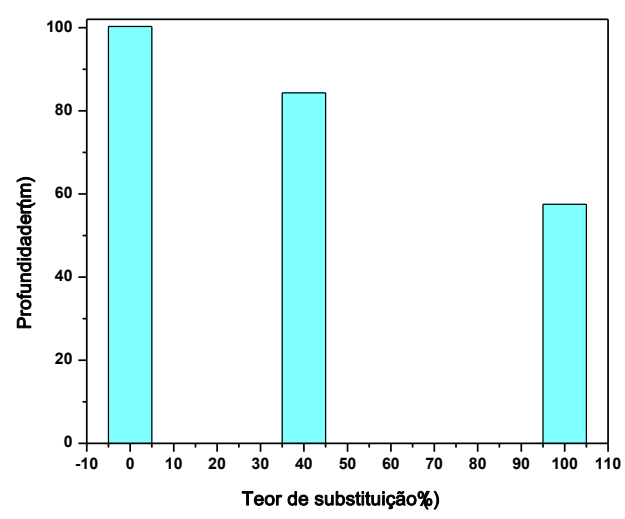

Figura 10: Profundidade de penetração de cloretos nos concretos.

Conforme resultados apresentados, constata-se que a substituição do agregado graúdo pelo resíduo 
cerâmico pode implicar em menor permeabilidade. Esse fato pode ser explicado pela formação dos principais produtos de hidratação, caso dos silicatos de cálcio hidratados $(\mathrm{C}-\mathrm{S}-\mathrm{H})$, este, em maior quantidade devido à provável ação pozolânica, causada pelos finos de materiais cerâmicos presentes nas misturas e, a cal hidratada, embora em menores quantidades.

$\mathrm{Na}$ Figura 11, são comparadas a microestrutura do concreto de referência (a) e os concretos com $100 \%$ de substituição de agregado natural (b), comparativamente às imagens obtidas por LEITE [5] (Figura 12).

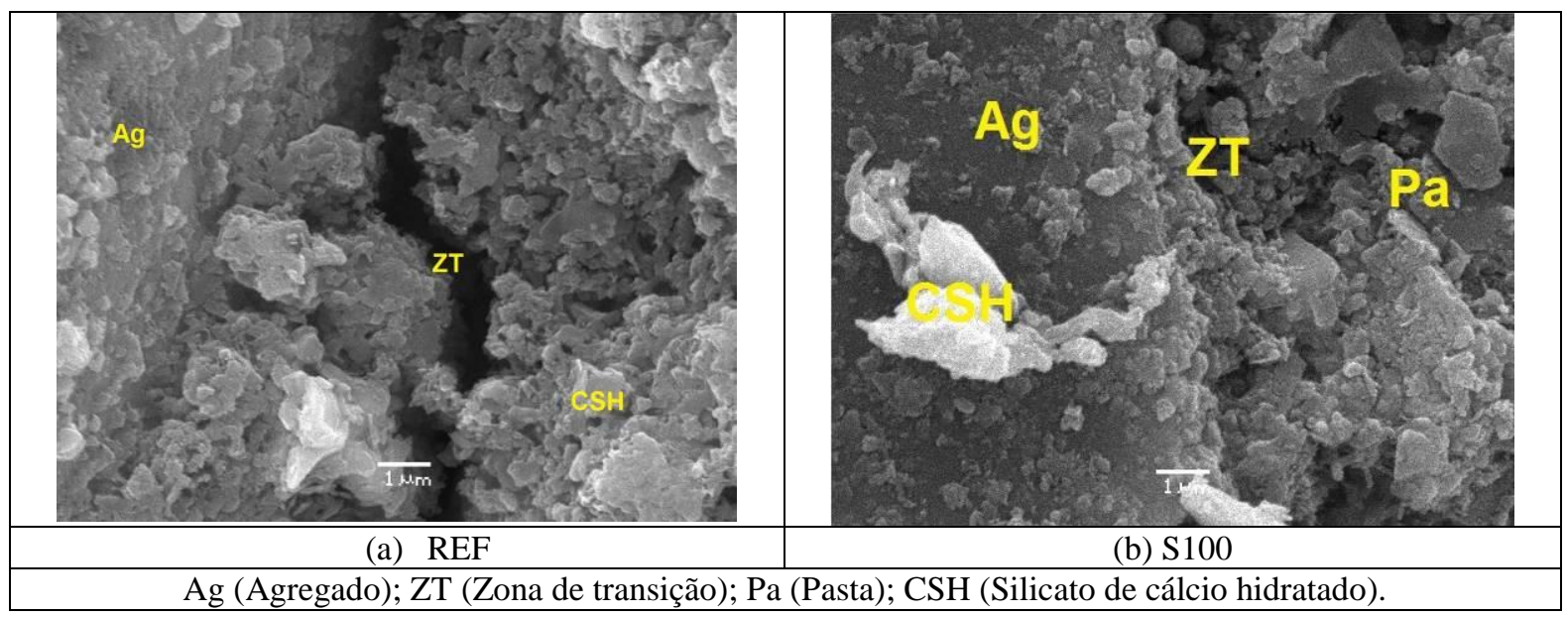

Figura 11: Microestrutura dos concretos de referência e com 100\% de substituição. Fonte: Autor.

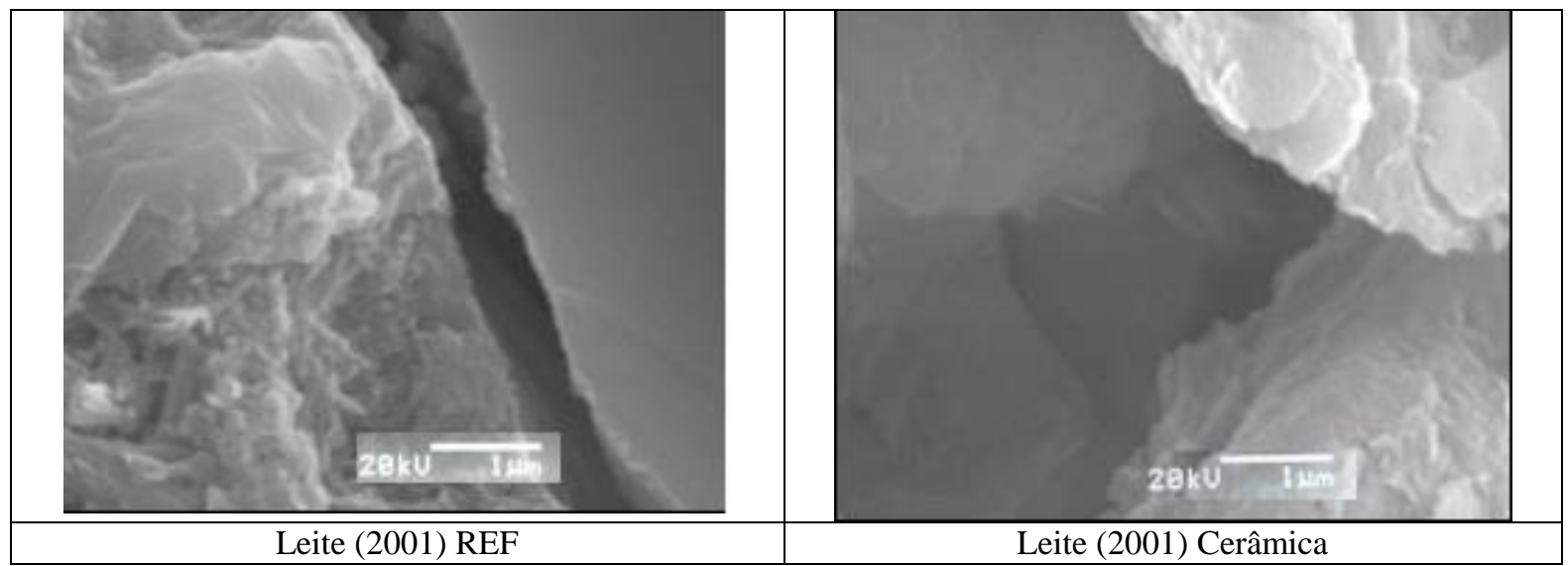

Figura 12: Microestrutura dos concretos de referência. Fonte: (Leite [5]).

Como apresentado, as imagens obtidas apresentam uma diminuição da zona de transição interfacial agregado cerâmico-matriz e corroboram o apresentado por Leite [5].

\section{CONCLUSÕES}

Neste trabalho foi avaliada a resistência mecânica e o desempenho em relação à durabilidade de concretos produzidos com agregados provenientes de resíduos cerâmicos, tendo em vista seu emprego na produção de elementos estruturais em concreto armado. No que se refere à resistência à compressão axial dos concretos analisados, na substituição de até $40 \%$ em volume de agregado graúdo pelo resíduo cerâmico, foi atendido o mínimo de $20 \mathrm{MPa}$, de acordo com a NBR 6118.

Especialmente relativo à carbonatação, se verificou uma profundidade de carbonatação excessiva, com relação água/cimento de 0,5 , mas com uma tendência de profundidades de carbonatação menores para concretos com até $40 \%$ de resíduo cerâmico. Isto foi atribuído a maior absorção de água do resíduo cerâmico, uma vez que pode influenciar diretamente na relação água/cimento e, também, possibilitar sua hidratação 
ao longo do tempo promovendo, assim, uma cura interna. Ambos os fenômenos colaboraram para maior compacidade da matriz cimentícia.

A absorção por permeabilidade capilar para os concretos com agregado graúdo de resíduo cerâmico apresentaram valores superiores ao do concreto de referência (REF), o que pode indicar que os diâmetros capilares foram reduzidos. De outra forma, os concretos produzidos com agregados graúdos de resíduos cerâmicos se comportaram melhor quanto à permeabilidade ao ar, ou seja, verificou-se que a substituição de agregado graúdo naturais por cerâmica vermelha possibilitaram à matriz cimentícia ficar menos porosa, promovendo maior impermeabilidade nas amostras analisadas.

Ao analisar separadamente os tipos de concreto, pôde-se observar, também, que em idades mais avançadas o coeficiente de permeabilidade ao ar diminui. Também foi observado que a profundidade de penetração de íons cloretos foram diretamente menores, quando aumentado o teor de substituição de agregado natural pelo reciclado cerâmico. Isto ocorre devido à cura interna, atribuída a maior absorção de água do resíduo cerâmico. Conclui-se neste trabalho que, no que diz respeito à durabilidade, os concretos produzidos com agregados graúdos de resíduos de cerâmica vermelha podem apresentar bom desempenho e viabilidade técnica para emprego em concretos de cimento Portland para fins estruturais.

\section{BIBLIOGRAFIA}

[1] CAMPOS, M.A., PAULON, V.A. "Utilização de agregados alternativos de isoladores elétricos de porcelana em concretos", Concreto y Cemento. Investigación y Desarrollo, v. 7, n. 1, pp.30-43, Julio -Diciembre de 2015 .

[2] MEDEIROS, M.H.F., ANDRADE,J.J.O., HELENE, P. Durabilidade e vida útil das estruturas de concreto, Concreto: Ciência e Tecnologia, IBRACON, 2011.

[3] ASSOCIAÇÃO BRASILEIRA DE NORMAS TÉCNICAS. NBR 6118: Projeto de estruturas de concreto -Procedimento. Rio de Janeiro, março 2014.

[4] RAISDORFER, J.W. "Influência da adição ou substituição de adições minerais ao cimento portland: Efeito na carbonatação, absorção capilar e resistividade de concretos”, Dissertação de MSc., Universidade Federal do Paraná, Curitiba, Paraná, 2015.

[5] LEITE, M.B. Avaliação de propriedades mecânicas de concretos produzidos com agregados reciclados de resíduos de construção e demolição, Tese de DSc., Escola de Engenharia, Universidade Federal do Rio Grande do Sul, Porto Alegre, 2001.

[6] VIEIRA, T., ALVES, A., BRITO, J., et al., "Durability - related performance of concrete containing fine recycled aggregates from crushed bricks and sanitary ware", Materials and design, v.90, pp.767-776, 2016.

[7] LEVY, S.M. Contribuição ao estudo da durabilidade de concretos produzidos com resíduos de concreto e alvenaria, Tese de DSc., Escola Politécnica, Universidade de São Paulo, São Paulo, 2002.

[8] SILVA, R.V., NEVES, R., BRITO, J., Carbonation behaviour of recycled aggregate concrete", Cement \& Concrete Composites, v. 62, pp.22-32, 2015.

[9] REIS, J.F.L. "Durabilidade do betão: Método da avaliação da carbonatação em condições gelo-degelo", Dissertação de MSc., Universidade da Beira Interior, Covilhã, Portugal, 2014.

[10] SENTHAMARAI, RM., MANOHARAN, P. D., GOBINATH, D. "Concrete made from ceramic industry waste: Durability properties”, Construction and Building Materials, v. 25, pp. 2413-2419, 2011.

[11] LOTFI, S., EGGIMANN, M., WAGNER, E., et al., "Performance of recycled aggregate concrete based on a new concrete recycling technology", Construction and Building Materials 95, 243-256, 2015.

[12] COROMINAS, A.G., ETXEBERRIA, M., POON, C.S., "Influence of the quality of recycled aggregates on the mechanical and durability properties of High Performance Concrete", Wascon 2015, Researchgate, June 2015.

[13] AMERICAN STANDARD FOR TESTING AND MATERIALS. ASTM C1202 -18: Standard Test Method for Electrical Indication of Concrete's Ability to Resist Chloride Ion Penetration. Philadelphia, 2017.

[14] SWISS SOCIETY OF ENGINEERS AND ARCHITECTS (SIA). (1989). Norma de ensayo Swiss Standard - SIA 162/1 - Succión Capilar.

[15] ASSOCIAÇÃO BRASILEIRA DE NORMAS TÉCNICAS. NBR NM 53: Agregado graúdo. Determinação da massa específica, massa específica aparente e absorção de água. Rio de Janeiro, jul. 2009. 
[16] ASSOCIAÇÃO BRASILEIRA DE NORMAS TÉCNICAS. NBR NM 52: Agregado miúdo. Determinação da massa específica e massa específica aparente . Rio de Janeiro, jul. 2009.

[17] ASSOCIAÇÃO BRASILEIRA DE NORMAS TÉCNICAS. NBR NM 248: Agregados. Determinação da composição granulométrica. Rio de Janeiro, jul. 2003.

[18] ASSOCIAÇÃO BRASILEIRA DE NORMAS TÉCNICAS. NBR NM 45: Agregados - Determinação da massa unitária e do volume de vazios. Rio de Janeiro, mar. 2006.

[19] ASSOCIAÇÃO BRASILEIRA DE NORMAS TÉCNICAS. NBR 7218. Agregados - Determinação do teor de argila em torrões e materiais friáveis. Rio de Janeiro, agosto 2010.

[20] ASSOCIAÇÃO BRASILEIRA DE NORMAS TÉCNICAS. NBR NM 46. Agregados - Determinação do material fino que passa através da peneira $75 \mu \mathrm{m}$, por lavagem. Rio de Janeiro, jul. 2003.

[21] ASSOCIAÇÃO BRASILEIRA DE NORMAS TÉCNICAS. NBR NM 30 Agregado miúdo - Determinação da absorção de água. Rio de Janeiro, jul. 2001.

[22] CORREIA, J.R., BRITO, J., PEREIRA,A.S. Effects on concrete durability of using ceramic aggregates, Materials and Structures, v.39, pp. 169-177, Technical University of Lisbon Instituto Superior Técnico, Portugal, 2006.

[23] ASSOCIAÇÃO BRASILEIRA DE NORMAS TÉCNICAS . NBR 15116 -Agregados reciclados de resíduos sólidos da construção civil-Utilização em pavimentação e preparo de concreto sem função estrutural. Rio de Janeiro, Set. 2004

[24] REUNION INTERNATIONALE DE LABORATOIRES D'ESSAIS ET MATERIAUX. CPC18: Measurement of hardened concrete carbonation depth, RILEM Recommendations CPC-18, Materials and Structures, [s. n.], pp. 453-455, 1988.

[25] ASSOCIAÇÃO BRASILEIRA DE NORMAS TÉCNICAS . NBR 9779 - Argamassa e concreto endurecidos - Determinação da absorção de água por capilaridade. Rio de Janeiro, set. 1995.

[26] THENOZ, B., "Measure de la perméabilité et de la poorosité des roches très compactes", G.R.A.S, v. 243, pp. 289-291, 1969.

[27] PEREIRA, V.M. "Permeabilidade ao Ar do Concreto", Dissertação de MSc., Faculdade de Engenharia Civil, Arquitetura e Urbanismo, Universidade Estadual de Campinas, Campinas São Paulo,2011.

[28] ITALIAN STANDARD UNI 7928. Norma Determination of chloride lon penetration,Roma, 1978.

[29] FERREIRA Jr. E. L., "Avaliação de propriedades de concretos de cimento Portland de alto forno e cimento Portland de alta resistência inicial submetidos a diferentes condições de cura", Dissertação de M.Sc., Faculdade de Engenharia Civil, Arquitetura e Urbanismo, Universidade Estadual de Campinas, 2003.

\section{ORCID}

Luciano Passos

Armando Lopes Moreno Junior

Carlos Eduardo Marmorato Gomes https://orcid.org/0000-0002-1477-1880

https://orcid.org/0000-0002-7660-050X

https://orcid.org/0000-0002-4366-6027 